\title{
Application of the ROV method for the selection of cutting fluids
}

\author{
Miloš Madić́, Miroslav Radovanović and Miodrag Manić
}

Faculty of Mechanical Engineering, University of Niš, A. Medvedeva 14, Niš, Serbia

\begin{tabular}{l}
\hline C H R O N I C L E \\
\hline Article history: \\
Received June 25, 2015 \\
Received in revised format: \\
October 12, 2015 \\
Accepted November 25, 2015 \\
Available online \\
November 26 2015 \\
\hline Keywords: \\
Cutting fluid \\
Multi-criteria decision making \\
Range of value
\end{tabular}

\section{Introduction}

During machining processes due to plastic deformation of workpiece material a much heat is generated in the cutting zone as a consequence of friction between cutting tools, chips and workpiece material. The heat generation increases the temperature of both the work piece and the tool point, resulting in decrease in hardness, and hence tool life. The prediction of a workpiece temperature is very important for cutting fluid selection (Tanikic, 2010). The machined surface will also be less smooth, and the possibility of built-up edge increases (Rao, 2007). In order to reduce the friction, heat transfer and to remove metal particles away from the cutting zone, during machining operation cutting fluids/lubricants are widely used in metal cutting industries (Abhang \& Hameedullah 2012). By reducing the friction, cutting forces during machining are decreased and also wear process of the cutting tool is slowed i.e. tool life is increased. The actual machining process can be carried out without the use of cutting fluids, but in this case the intensity of tool wear is high and the machined surface is of lower quality (Radovanović, 2002).

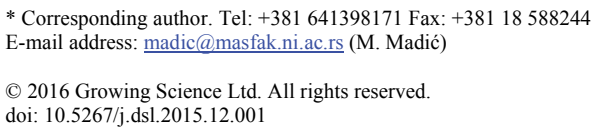


Cutting fluids/lubricants have different effects including cooling, lubricating, mechanical, diffuse and flushing. Besides cutting fluids should fulfill some additional requirements i.e. they should not be harmful to human health and environment, they should be readily biodegradable and they should not generate smoke when machining (Radovanović, 2002). Since cutting fluids serve many useful functions during machining, and on the other hand incur a major portion of the total manufacturing cost (Klocke \& Eisenblätter 1997), the appropriate selection of cutting fluids is very important. Selection of the most suitable cutting fluid in any machining process must be carried out to obtain a maximum benefit (Çakīr et al., 2007). However, as noted by Rao (2007), since there is almost no standardized method available for this purpose, the selection of cutting fluids is more an art, than a science. The existing procedure of cutting fluid selection for any given machining application is mainly defined considering the used cutting tools, workpiece material combination and the machining process itself (Rao, 2007; Abhang \& Hameedullah 2012).

The most important parameter in the selection of cutting fluids is the characteristics of machining process. Variety of machining processes would indicate relation between workpiece material-cutting tool-chip combinations. The most difficult machining process will need to use more cutting fluid (Çakīr et al., 2007). The competitive cutting fluids are usually evaluated by considering some important machining performance measures i.e. criteria such as tool wear, cutting forces, temperature in the cutting zone, power consumption, surface finish, material removal rate, dimensional accuracy etc. In order to deal with a number of conflicting criteria in a systematical approach decision makers in manufacturing environment i.e. production engineers can rely on the use of multi-criteria decision making (MCDM) methods which have been proven as powerful mathematical tools for solving ranking and selection problems. From the literature it appears that there are still only few applications of MCDM methods for solving the lubricant/cutting fluids selection problems.

Rao and Gandhi (2002) proposed graph theory and matrix approach (GTMA) method for the selection, identification and comparison of cutting fluids. Sun et al. (2001) reported a two-grade fuzzy synthetic decision-making system with use of an analytic hierarchy process (AHP) for evaluating the performance of grinding fluids. Tan et al. (2002) developed a multi-objective decision making model for the cutting fluid selection in the gear hobbing process. The obtained results showed practically and usefulness of the developed model. For the performance evaluation of cutting fluids for green manufacturing Rao (2004) proposed a combined multiple attribute decision making method. Rao (2007) demonstrated the application of different MCDM methods such as GTMA, simple additive weighting (SAW) method, weighted product method (WPM), AHP and its versions, technique for order of preference by similarity to ideal solution (TOPSIS) and modified TOPSIS methods on two examples. Rao and Patel (2010) presented an approach for the selection of cutting fluids by using improved preference ranking organization method for enrichment evaluation (PROMETHEE) method. Abhang and Hameedullah (2012) applied combined TOPSIS and AHP method for the selection of cutting fluids while machining En-31 steel workpiece with tungsten carbide inserts. Chakraborty and Zavadskas (2014) investigated the applicability of weighted aggregated sum product assessment (WASPAS) method for solving different decision making problems in manufacturing environment, including the cutting fluid selection problem.

Deshamukhya and Ray (2014) by using AHP method developed a decision support system in the unstructured environment in order to select the optimum cutting fluid which will result in least environmental impacts. Three cutting fluids were considered for the purpose and the one with most favorable qualities was considered as the optimum cutting fluid which will favor green manufacturing. The proposed model considered the following criteria: environmental impact, cost and qualities. The MCDM model developed by Deshamukhya and Ray (2014) was used by Jagadish and Ray (2014) for the purpose of analysis of the recently developed MCDM method, i.e. multi-objective optimisation on the basis of simple ratio analysis (MOOSRA) method. Tiwari and Sharma (2015) defined decision matrix for selection of the most suitable cutting fluid in the case of turning of AISI304L. For the purpose 
of evaluation and ranking of several vegetable and commercial cutting fluid two MCDM methods were applied.

In this paper an attempt has been made to investigate the applicability of an almost unexplored MCDM method, i.e. range of value (ROV) method for solving the cutting fluid selection problems. The main motivation of using the ROV method is that it offers a very simple computational procedure compared to other MCDM methods, and moreover, till date this method has very limited applications in the machining domain. Three case studies dealing with selection of the most suitable cutting fluid for the given machining application were solved to demonstrate its applicability and effectiveness. The results obtained using the ROV method were compared with the results of other MCDM methods used by previous researchers.

\section{Range of value method}

The range of value (ROV) method was proposed by Yakowitz et al. (1993). This method requires only ordinal specification of criteria importance from a decision maker. Thus, in situations where decision makers are facing problems in supplying quantitative weights, the application of the ROV method can be particularly useful (Hajkowicz \& Higgins 2008).

The application of any MCDM method for solving a decision-making problem usually involves the three main steps, i.e. $i$ ) determination of the relevant conflicting criteria and feasible alternatives, $i i$ ) measurement of the relative importance of the considered criteria and impact of the alternatives on those criteria, and iii) determination of the performance measures of the alternatives for ranking (Chakraborty and Chatterjee 2013). The procedure of the application of the MOORA method is simple and consists of the following steps:

Step 1: The ROV method starts with setting the goals and identification of the relevant criteria for evaluating available alternatives.

Step 2: In this step, based on the available information about the alternatives, decision-making matrix or decision table is set. Each row refers to one alternative, and each column to one criterion. The initial decision matrix, $X$, is:

$$
X=\left[x_{i j}\right]=\left[\begin{array}{cccc}
x_{11} & x_{12} & \ldots & x_{1 n} \\
x_{21} & x_{22} & \ldots & x_{2 n} \\
\ldots & \ldots & \ldots & \ldots \\
x_{m 1} & x_{m 2} & \ldots & x_{m n}
\end{array}\right]
$$

where $x_{i j}$ is the performance measure of $i$-th alternative with respect to $j$-th criterion, $m$ is the number of alternatives and $n$ is the number of criteria.

Step 3. In this step performance measures of alternatives are normalized - defining values $\bar{x}_{i j}$ of normalised decision-making matrix $\bar{X}$.

$$
\bar{X}=\left[\bar{x}_{i j}\right]_{m \times n}=\left[\begin{array}{cccc}
\bar{x}_{11} & \bar{x}_{12} & \ldots & \bar{x}_{1 n} \\
\bar{x}_{21} & \bar{x}_{22} & \ldots & \bar{x}_{2 n} \\
\ldots & \ldots & \ldots & \ldots \\
\bar{x}_{m 1} & \bar{x}_{m 2} & \ldots & \bar{x}_{m n}
\end{array}\right]
$$


For beneficial criteria, whose preferable values are maxima, normalization is done by using linear transformation (Hajkowicz \& Higgins, 2008):

$$
\bar{x}_{i j}=\frac{x_{i j}-\min _{i=1}^{m}\left(x_{i j}\right)}{\max _{i=1}^{m}\left(x_{i j}\right)-\min _{i=1}^{m}\left(x_{i j}\right)}
$$

For non-beneficial criteria, whose preferable values are minima, normalization is done by:

$$
\bar{x}_{i j}=\frac{\max _{i=1}^{m}\left(x_{i j}\right)-x_{i j}}{\max _{i=1}^{m}\left(x_{i j}\right)-\min _{i=1}^{m}\left(x_{i j}\right)}
$$

Step 4. The application of the ROV method involves the calculation of the best and worst utility for each alternative. This is achieved by maximizing and minimizing a utility function. For a linear additive model, the best utility $\left(u_{i}^{+}\right)$and the worst utility $\left(u_{i}^{-}\right)$of $i$-th alternative are obtained using the following equations (Hajkowicz and Higgins 2008; Athawale and Chakraborty 2011):

$$
\begin{aligned}
& \text { Maximize: } u_{i}^{+}=\sum_{j=1}^{n} \bar{x}_{i j} \cdot w_{j} \\
& \text { Minimize: } u_{i}^{-}=\sum_{j=1}^{n} \bar{x}_{i j} \cdot w_{j}
\end{aligned}
$$

where $w_{j}(j=1, \ldots, n)$ are criteria weights which satisfy $\sum_{j=1}^{n} w_{j}=1$ and $w_{j} \geq 0$.

If $u_{i}^{-}>u_{i}^{+}$then alternative $i$ outperforms alternative $i$ ' regardless of the actual quantitative weights. If it is not possible differentiate the options on this basis then a scoring (enabling subsequent ranking) can be attained from the midpoint, which can be calculated as (Hajkowicz \& Higgins 2008; Athawale \& Chakraborty, 2011):

$u_{i}=\frac{u_{i}^{-}+u_{i}^{+}}{2}$

Step 5. In this final step the complete ordinal ranking of the alternatives is obtained on the basis of $u_{i}$ values. Thus, the best alternative has the highest $u_{i}$ value and the worst alternative has the lowest $u_{i}$ value.

\section{Illustrative examples}

In order to demonstrate computation and applicability of the ROV method for solving cutting fluid selection problem, the following four case studies are illustrated. In each case study the results obtained by previous researchers using different MCDM methods and the results obtained using the ROV method were compared and discussed.

\subsection{Case study 1}

Rao and Patel (2010) presented an improved PROMETHEE based approach for solving cutting fluid selection problem for a cylindrical grinding operation. Four cutting fluid i.e. alternatives were evaluated based on eight criteria such as wheel wear (WW), tangential force (TF), grinding temperature (GT), surface roughness $(\mathrm{SR})$, recyclability $(\mathrm{R})$, toxic harm rate $(\mathrm{TH})$, environment pollution tendency $(\mathrm{EP})$ and stability (S). Four cutting fluid properties, i.e. R, TH, EP and S were expressed in linguistic terms 
which were converted to corresponding fuzzy scores as explained by Rao (2007). Among the eight selection criteria, $\mathrm{R}$ and $\mathrm{S}$ are the only beneficial criteria. The data for this cutting fluid selection problem are given in Table 1.

\section{Table 1}

Decision matrix for case study 1 (Rao and Patel 2010)

\begin{tabular}{ccccccccc}
\hline Cutting fluid & $\begin{array}{c}\text { WW } \\
(\mathrm{mm})\end{array}$ & $\begin{array}{c}\text { TF } \\
(\mathrm{N})\end{array}$ & $\begin{array}{c}\text { GT } \\
\left({ }^{\circ} \mathrm{C}\right)\end{array}$ & $\begin{array}{c}\text { SR } \\
(\mu \mathrm{m})\end{array}$ & R & TH & EP & S \\
\hline 1 & 0.035 & 34.5 & 847 & 1.76 & $\mathrm{~L}(0.335)$ & $\mathrm{A}(0.5)$ & AA $(0.59)$ & AA $(0.59)$ \\
2 & 0.027 & 36.8 & 834 & 1.68 & $\mathrm{~L}(0.335)$ & $\mathrm{H}(0.665)$ & H $(0.665)$ & H $(0.665)$ \\
3 & 0.037 & 38.6 & 808 & 2.4 & AA $(0.59)$ & AA $(0.59)$ & BA $(0.41)$ & A $(0.5)$ \\
4 & 0.028 & 32.6 & 821 & 1.59 & A $(0.5)$ & AA $(0.59)$ & AA $(0.59)$ & BA $(0.41)$ \\
\hline
\end{tabular}

L - low; BA - below average; A - average; AA: above average; $\mathrm{H}$ - high

By using the AHP method, Rao and Patel (2010) determined criteria weights as: $w_{W W}=0.3306$, $w_{T F}=0.0718, w_{G T}=0.1808, w_{S R}=0.0718, w_{R}=0.0459, w_{T H}=0.126, w_{E P}=0.126$ and $w_{S}=0.0472$. This set of criteria weights was employed here for the ROV method-based analysis. The detailed computational procedure of the ROV method for solving the cutting fluid selection problem is as follows. Firstly by using Eqs. 3 and 4 for beneficial and non-beneficial criteria, respectively, the normalized decisionmaking matrix is obtained (Table 2).

Table 2

Normalized decision matrix for case study 1

\begin{tabular}{ccccccccc}
\hline Cutting fluid & $\begin{array}{c}\text { WW } \\
(\mathrm{mm})\end{array}$ & $\begin{array}{c}\text { TF } \\
(\mathrm{N})\end{array}$ & $\begin{array}{c}\mathrm{GT} \\
\left({ }^{\circ} \mathrm{C}\right)\end{array}$ & $\begin{array}{c}\text { SR } \\
(\mu \mathrm{m})\end{array}$ & $\mathrm{R}$ & $\mathrm{TH}$ & EP & $\mathrm{S}$ \\
\hline 1 & 0.2000 & 0.6833 & 0 & 0.7901 & 0 & 1 & 0.2941 & 0.7059 \\
2 & 1 & 0.3 & 0.3333 & 0.8889 & 0 & 0 & 0 & 1 \\
3 & 0 & 0 & 1 & 0 & 1 & 0.4545 & 1 & 0.3529 \\
4 & 0.9 & 1 & 0.6667 & 1 & 0.6471 & 0.4545 & 0.2941 & 0 \\
\hline
\end{tabular}

Subsequently, by using Eq. (5) and Eq. (6) the best and the worst utility functions for each alternative were calculated. Finally, the $u_{i}$ values of all alternatives with respect to the considered criteria were estimated by using Eq. (7). Table 3 exhibits results of the ROV method upon which complete ranking of the cutting fluids was obtained.

\section{Table 3}

Computational details of the ROV method for case study 1

\begin{tabular}{ccccc}
\hline Cutting fluid & $u_{i}{ }^{+}$ & $u_{i}{ }^{-}$ & $u_{i}$ & Rank \\
\hline 1 & 0.0333 & 0.3350 & 0.1841 & 4 \\
2 & 0.0472 & 0.4762 & 0.2617 & 2 \\
3 & 0.0626 & 0.3641 & 0.2133 & 3 \\
4 & 0.0297 & 0.6560 & 0.3429 & 1 \\
\hline
\end{tabular}

As could be seen from Table 3 by applying the ROV method, the ranking of cutting fluids is obtained as 4-2-3-1. Cutting fluid 4 is observed to be the most appropriate for this machining application. Cutting fluid 2 has the second preference and cutting fluid 1 is the least favored. By applying the PROMETHEE method, Rao and Patel (2010) derived a ranking list of the alternatives as 4-2-3-1. It can be observed that the complete ranking order of the alternatives obtained by ROV and PROMETHEE methods perfectly matches. The same cutting fluid selection problem was solved by Chakraborty and Zavadskas (2014) by applying the recently developed weighted aggregated sum product assessment (WASPAS) 
method. For $\lambda>0.5$ ( $\lambda$ is parameter that figure in WASPAS method having values between 0 and 1$)$, the application of the WASPAS method produces the same ranking as ROV and PROMETHEE methods.

\subsection{Case study 2}

In order to select a right lubricant from amongst a number of lubricants during the machining of En-31 steel work piece with tungsten carbide inserts, Abhang and Hameedullah (2012) applied combined MCDM approach. The selection procedure was based on a combined TOPSIS and AHP methods. Abhang and Hameedullah (2012) considered chip-tool interface temperature $\left(T_{c}\right)$, cutting force $\left(F_{c}\right)$, tool wear $\left(\mathrm{T}_{\mathrm{w}}\right)$ and surface roughness $\left(\mathrm{R}_{\mathrm{a}}\right)$ as selection criteria. All these criteria belong to the category of so called non-beneficial criteria where smaller values are desirable. Also these are quantitative in nature, having absolute numerical values obtained after conducting three experimental trials for each cutting condition. In the experiment, dry, wet and minimum quantity of cutting fluid (graphite, $\mathrm{MoS}_{2}$ and boric acid powder mixed with base oil SAE-40 by weight separately) for environmentally conscious manufacturing process were investigated. In sum, 9 cutting conditions i.e. alternatives were analyzed. Based on experimental data, Abhang and Hameedullah (2012) developed the following decision matrix (Table 4).

\section{Table 4}

Decision matrix for case study 2 (Abhang \& Hameedullah 2012)

\begin{tabular}{cccccc}
\hline Cutting condition & Cutting fluid/lubricant & $\begin{array}{c}\mathrm{T}_{\mathrm{c}} \\
\left({ }^{\circ} \mathrm{C}\right)\end{array}$ & $\begin{array}{c}\mathrm{F}_{\mathrm{c}} \\
(\mathrm{N})\end{array}$ & $\begin{array}{c}\mathrm{T}_{\mathrm{w}} \\
(\mathrm{mg} / \mathrm{min})\end{array}$ & $\begin{array}{c}\mathrm{R}_{\mathrm{a}} \\
(\mu \mathrm{m})\end{array}$ \\
\hline 1 & Dry & 427 & 253.61 & 0.338 & 12.51 \\
2 & Wet & 390 & 221.6 & 0.336 & 10.97 \\
3 & $10 \%$ graphite + SAE-40 base oil & 363 & 228 & 0.276 & 10.74 \\
4 & $10 \%$ MOS2 + SAE-40 base oil & 351 & 230 & 0.274 & 10.68 \\
5 & $10 \%$ boric acid + SAE-40 base oil & 320 & 155.2 & 0.249 & 10.48 \\
6 & $15 \%$ graphite + SAE-40 base oil & 386 & 218 & 0.28 & 10.7 \\
7 & $15 \%$ MOS2 + SAE-40 base oil & 365 & 228 & 0.276 & 10.53 \\
8 & $15 \%$ boric acid + SAE-40 base oil & 326.88 & 256.96 & 0.247 & 10.45 \\
9 & SAE-40 base oil & 378 & 229 & 0.335 & 10.8 \\
\hline
\end{tabular}

Using the AHP method, Abhang and Hameedullah (2012) determined the relative importance of criteria i.e. the criteria weights were obtained as: $w_{T_{c}}=0.6938, w_{F_{c}}=0.1392, w_{T_{w}}=0.1225$ and $w_{R_{a}}=0.0444$. For the comparison purpose in this paper the same criteria weights were used for the ROV method-based analysis. First, by using Eq. (3) and Eq. (4) for beneficial and non-beneficial criteria, respectively, the normalized decision-making matrix is obtained. Subsequently, by applying Eq. (5) and Eq. (6), the best and the worst utility functions for each alternative were calculated. Finally, the $u_{i}$ values of all alternatives with respect to the considered criteria were estimated by using Eq. (7). The computational details of the ROV method for the case study 2 are given in Table 5. Note, since there were no beneficial criteria, $u_{i}{ }^{+}$values for all alternatives are equal to 0 .

Table 5

Computational details of the ROV method for case study 2

\begin{tabular}{cccccc}
\hline Cutting condition & Cutting fluid/lubricant & $u_{i}^{+}$ & $u_{i}{ }^{+}$ & $u_{i}$ & Rank \\
\hline 1 & Dry & 0 & 0.0046 & 0.0023 & 9 \\
2 & Wet & 0 & 0.3242 & 0.1621 & 8 \\
3 & $10 \%$ graphite + SAE-40 base oil & 0 & 0.5762 & 0.2881 & 4 \\
4 & $10 \%$ MOS2 + SAE-40 base oil & 0 & 0.6553 & 0.3276 & 3 \\
5 & $10 \%$ boric acid + SAE-40 base oil & 0 & 0.9966 & 0.4983 & 1 \\
6 & $15 \%$ graphite + SAE-40 base oil & 0 & 0.4362 & 0.2181 & 6 \\
7 & $15 \%$ MOS2 + SAE-40 base oil & 0 & 0.5678 & 0.2839 & 5 \\
8 & $15 \%$ boric acid + SAE-40 base oil & 0 & 0.8161 & 0.4080 & 2 \\
9 & SAE-40 base oil & 0 & 0.3969 & 0.1984 & 7 \\
\hline
\end{tabular}


As could be seen from Table 5 by applying the ROV method, ranking of cutting fluids is obtained as 5-8-4-3-7-6-9-2-1. It is observed that that the 10\% boric acid mixed with SAE-40 base oil is the best cutting fluid. On the other hand dry machining represents the least preferred cutting condition. By applying the combined TOPSIS and AHP methods, Abhang and Hameedullah (2012) obtained the ranking list of the cutting fluids as 5-8-4-3-7-6-9-2-1. Again, it can be observed that the complete ranking order of the alternatives obtained by ROV and TOPSIS methods perfectly matches.

\subsection{Case study 3}

Rao (2007) presented the results of a cylindrical turning conducted for the purpose of evaluation of most common, commercially available metal cutting fluids, namely, water soluble, straight mineral, chlorinated and sulfo-chlorinated oils. Workpiece material was medium carbon steel. A HSS tool was used for the experiment conducted by using cutting speed of $33.5 \mathrm{~m} / \mathrm{min}$ and feed rate of $0.24 \mathrm{~mm} / \mathrm{rev}$. In the MCDM model four non-beneficial criteria were selected such as cutting force $\left(\mathrm{F}_{\mathrm{c}}\right)$, thrust force $\left(F_{t}\right)$, wear land $(\mathrm{WL})$ and processed surface roughness $\left(\mathrm{R}_{\mathrm{rms}}\right)$. The quantitative assessments of 5 cutting conditions i.e. alternatives with respect to considered criteria are given in Table 6.

\section{Table 6}

Decision matrix for case study 3 (Rao 2007)

\begin{tabular}{lcccc}
\hline Cutting fluid & $\begin{array}{c}\mathrm{F}_{\mathrm{c}} \\
(\mathrm{N})\end{array}$ & $\begin{array}{c}\mathrm{F}_{\mathrm{t}} \\
(\mathrm{N})\end{array}$ & WL (mm*100) & $\begin{array}{c}\mathrm{R}_{\mathrm{rms}} \\
(\mu \mathrm{m})\end{array}$ \\
\hline Dry & 1324 & 725 & 7 & 9 \\
Water soluble & 1082 & 485 & 16 & 7 \\
Straight mineral oil & 1098 & 516 & 8 & 4.7 \\
Chlorinated oil & 1158 & 494 & 15 & 4.9 \\
Sulfo-chlorinared oil & 962 & 393 & 6 & 8 \\
\hline
\end{tabular}

Rao (2007) considered this case study to demonstrate the application of the GTMA and MCDM methods for cutting fluid selection. The criteria weights used in the application of these MCDM methods were: $w_{F_{c}}=0.3, w_{F_{t}}=0.1, w_{W L}=0.4$ and $w_{R_{m s}}=0.2$. For the comparison purpose, in this paper the same criteria weights were used for the ROV method-based analysis. Following the same computational procedure as explained in detail in the previous case studies, the complete ranking of the considered cutting fluids is obtained. The computational details of the ROV method for solving this cutting fluid selection problem are given in Table 7. Again, since there were no beneficial criteria, $u_{i}{ }^{+}$ values for all alternatives are equal to 0 .

Table 7

Computational details of the ROV method for case study 3

\begin{tabular}{lcccc}
\hline Cutting fluid & $u_{i}^{+}$ & $u_{i}^{-}$ & $u_{i}$ & Rank \\
\hline Dry & 0 & 0.3600 & 0.1800 & 5 \\
Water soluble & 0 & 0.3659 & 0.1829 & 4 \\
Straight mineral oil & 0 & 0.7702 & 0.3851 & 2 \\
Chlorinated oil & 0 & 0.4378 & 0.2189 & 3 \\
Sulfo-chlorinared oil & 0 & 0.8465 & 0.4233 & 1 \\
\hline
\end{tabular}

As could be observed from Table 7 it is understood that the sulfo-chlorinated oil is the best choice among the cutting fluids considered for the cylindrical turning operation under the given conditions. The last choice is dry cutting. The comparison of the obtained complete ranking of the cutting fluid with those derived by Rao (2007) using GTMA and different MCDM methods is given in Table 8 . From Table 8 it is observed that sulfo-chlorinared and straight mineral oil have been identified as the first and second choice cutting fluids by all MCDM methods. Although there are slight discrepancies between lower-ranked cutting fluids, similar ranking performance of these MCDM methods for this particular machining application is obvious. 


\section{Table 8}

Rankings of the cutting fluids obtained using different MCDM methods

\begin{tabular}{lccccccc}
\hline & ROV & GTMA & SAW & WPM & AHP & TOPSIS & Modified TOPSIS \\
\hline Dry & 5 & 5 & 5 & 5 & 5 & 3 & 4 \\
Water soluble & 4 & 4 & 3 & 4 & 4 & 5 & 5 \\
Straight mineral oil & 2 & 2 & 2 & 2 & 2 & 2 & 2 \\
Chlorinated oil & 3 & 3 & 4 & 3 & 3 & 4 & 3 \\
Sulfo-chlorinared oil & 1 & 1 & 1 & 1 & 1 & 1 & 1 \\
\hline
\end{tabular}

\subsection{Case study 4}

Tiwari and Sharma (2015) compared two MCDM methods, i.e., simple additive weighting (SAW) method and weighted product method (WPM) for the selection of the cutting fluid for turning process of AISI304L. Several environmental friendly vegetable based cutting fluids including different percentage of extreme pressure additives and two commercial fluids (semi-synthetic and mineral cutting fluids) were evaluated considering five criteria: surface roughness $\left(R_{a}\right)$, cutting force $\left(F_{c}\right)$, feed force $\left(\mathrm{F}_{\mathrm{f}}\right)$, flank wear $(\mathrm{FW})$ and nose wear $(\mathrm{NW})$. Based on experimental data, Tiwari and Sharma (2015) developed the following decision matrix (Table 9).

Table 9

Decision matrix for case study 4 Tiwari and Sharma (2015)

\begin{tabular}{llllll}
\hline Cutting fluid & $\mathrm{R}_{\mathrm{a}}(\mu \mathrm{m})$ & $\mathrm{F}_{\mathrm{c}}(\mathrm{N})$ & $\mathrm{F}_{\mathrm{f}}(\mathrm{N})$ & $\mathrm{FW}(\mathrm{mm})$ & $\mathrm{NW}(\mathrm{mm})$ \\
\hline SCF-II $(8 \%$ of EP) & 3.47 & 635.15 & 439.59 & 0.1793 & 0.1505 \\
SCF-II $(12 \%$ of EP) & 3.93 & 627.39 & 423.8 & 0.1881 & 0.1682 \\
CCF-II $(8 \%$ of EP) & 3.06 & 629.26 & 401.53 & 0.1527 & 0.1316 \\
CCF-II $(12 \%$ of EP) & 3.75 & 668.12 & 495.04 & 0.1962 & 0.1616 \\
CMCF & 4.75 & 663.26 & 544.86 & 0.1949 & 0.2339 \\
CSSCF & 4.01 & 615.05 & 523.93 & 0.2436 & 0.2094 \\
Dry cutting & 3.3 & 503.15 & 271.14 & 0.54 & 0.5357 \\
\hline
\end{tabular}

For the comparison purpose, in this paper the same criteria weights were used for the ROV methodbased analysis. Since all criteria were considered to be of equal importance, 0.2 weight value was assigned for each criterion. Following the same computational procedure as explained in detail in the previous case studies, the complete ranking of the considered cutting fluids is obtained. The computational details of the ROV method for solving this cutting fluid selection problem are given in Table 10. Again, since there were no beneficial criteria, $u_{i}{ }^{+}$values for all alternatives are equal to 0 .

Table 10

Computational details of the ROV method for case study 3

\begin{tabular}{lllll}
\hline Cutting fluid & $u_{i}{ }^{+}$ & $u_{i}{ }^{-}$ & $u_{i}$ & Rank \\
\hline SCF-II $(8 \%$ of EP) & 0 & 0.645278 & 0.322639 & 2 \\
SCF-II (12\% of EP) & 0 & 0.598481 & 0.29924 & 3 \\
CCF-II (8\% of EP) & 0 & 0.751839 & 0.37592 & 1 \\
CCF-II (12\% of EP) & 0 & 0.517434 & 0.258717 & 5 \\
CMCF & 0 & 0.333469 & 0.166735 & 7 \\
CSSCF & 0 & 0.48176 & 0.24088 & 6 \\
Dry cutting & 0 & 0.571598 & 0.285799 & 4 \\
\hline
\end{tabular}

As could be observed from Table 10, CCF-II ( $8 \%$ of EP), i.e. canola based cutting fluid with $8 \%$ of extreme pressure (EP) additive is the best choice among the cutting fluids considered for the given turning application. The comparison of the obtained complete ranking of the cutting fluid with those derived by Tiwari and Sharma (2015) using SAW and WPM methods is given in Table 11. From Table 11 it is observed that there exists a good correlation between ranking list obtained by ROV, SAW and WPM methods. It is estimated that correlation coefficient of 0.964 exists between ROV and SAW methods, and that correlation coefficient of 0.786 between ROV and WPM methods. 
Table 11

Rankings of the cutting fluids obtained using different MCDM methods

\begin{tabular}{llll}
\hline Cutting fluid & ROV & SAW & WPM \\
\hline SCF-II (8\% of EP) & 2 & 2 & 2 \\
SCF-II (12\% of EP) & 3 & 3 & 3 \\
CCF-II (8\% of EP) & 1 & 1 & 1 \\
CCF-II (12\% of EP) & 5 & 4 & 4 \\
CMCF & 7 & 7 & 6 \\
CSSCF & 6 & 6 & 5 \\
Dry cutting & 4 & 5 & 7 \\
\hline
\end{tabular}

\section{Conclusions}

Due to the presence of a number of machining processes-cutting tool material-workpiece material combinations and lack of enough expertise and knowledge in the field, it becomes quite difficult for the manufacturing engineers to select the most appropriate cutting fluid/lubricant for a given machining application. Although a good amount of MCDM methods have been proposed for dealing with complex selection problems, only few have been previously applied in the selection of the most appropriate cutting fluid. In this paper an almost unexplored MCDM method, i.e. range of value (ROV) method was applied for solving cutting fluid selection problems. Four case studies demonstrated the potentiality, applicability and usefulness of the ROV method.

On the basis of the obtained results it is observed that in comparison to other MCDM methods, AHP, TOPSIS, PROMETHEE, etc., the ROV method is very simple to comprehend and easy to implement. Actually the method is very simple and can be readily implemented in few steps using MS Excel. Moreover, its calculation procedure is not affected by the introduction of any additional parameters (e.g., $\lambda$ in WASPAS method) as it happens in case of other MCDM methods. The implementation of the ROV method does not necessarily require strong background in mathematics and operational research which is an additional advantage of the method to be implemented by the manufacturing engineers in real industrial praxis. As the cutting fluid/lubricant selection problems may consist of both the qualitative and quantitative criteria, the ROV method is quite suitable to deal with these types of decision making problems.

The presented ROV-based MCDM methodology can be used for any type of selection problems involving any number of criteria. Application of the ROV method for solving a wide range of ranking and selection problems in real-time manufacturing environment is future research scope.

\section{Acknowledgements}

This work was carried out within the project TR 35034 financially supported by the Ministry of Education and Science of the Republic of Serbia.

\section{References}

Abhang, L. B., \& Hameedullah, M. (2012). Selection of lubricant using combined multiple attribute decision making method. Advances in Production Engineering \& Management, 7(1), 39-50.

Athawale, V. M., \& Chakraborty, S. (2011). A comparative study on the ranking performance of some multi-criteria decision-making methods for industrial robot selection. International journal of industrial engineering computations, 2(4), 831-850.

Çakīr, O., Yardimeden, A., Ozben, T., \& Kilickap, E. (2007). Selection of cutting fluids in machining processes. Journal of Achievements in materials and Manufacturing engineering, 25(2), 99-102. 
Chakraborty, S., \& Chatterjee, P. (2013). Selection of materials using multi-criteria decision-making methods with minimum data. Decision Science Letters, 2(3), 135-148.

Chakraborty, S., \& Zavadskas, E. K. (2014). Applications of WASPAS method in manufacturing decision making. Informatica, 25(1), 1-20.

Deshamukhya, T., \& Ray, A. (2014). Selection of cutting fluid for green manufacturing using analytical hierarchy process (AHP): a case study. International Journal of Mechanical Engineering and Robotics Research, 3, 174-182.

Hajkowicz, S., \& Higgins, A. (2008). A comparison of multiple criteria analysis techniques for water resource management. European journal of operational research, 184(1), 255-265.

Jagadish, A., \& Ray, A. (2014). Green cutting fluid selection using MOOSRA method. International Journal of Research in Engineering and Technology, 3(3), 559-563.

Klocke, F., \& Eisenblätter, G. (1997). Dry cutting. CIRP Annals-Manufacturing Technology, 46(2), 519-526.

Radovanović, M. (2002). Technology of Machinery. Faculty of Mechanical Engineering, University of Niš.

Rao, R. V. (2004). Performance evaluation of cutting fluids for green manufacturing using a combined multiple attribute decision making method.International Journal of Environmentally Conscious Design and Manufacturing, 12(2), 526-535.

Rao, R. V. (2007). Decision Making in the Manufacturing Environment: Using Graph Theory and Fuzzy Multiple Attribute Decision Making Methods. Springer.

Rao, R. V., \& Gandhi, O. P. (2002). Digraph and matrix methods for the machinability evaluation of work materials. International Journal of Machine Tools and Manufacture, 42(3), 321-330.

Venkata Rao, R., \& Patel, B. K. (2010). Decision making in the manufacturing environment using an improved PROMETHEE method.International Journal of Production Research, 48(16), 46654682.

Singh, T., Gupta, M., \& Sharma, M. A. (2015). Stock market liquidity and firm performance. Accounting, 1(1), 29-36.

Sun, J., Ge, P., \& Liu, Z. (2001). Two-grade fuzzy synthetic decision-making system with use of an analytic hierarchy process for performance evaluation of grinding fluids. Tribology international, 34(10), 683-688.

Tan, X. C., Liu, F., Cao, H. J., \& Zhang, H. (2002). A decision-making framework model of cutting fluid selection for green manufacturing and a case study. Journal of Materials processing technology, 129(1), 467-470.

Tanikić, D., Manić, M., Devedžić, G., \& Stević, Z. (2010). Modelling metal cutting parameters using intelligent techniques. Strojniški vestnik-Journal of Mechanical Engineering, 56(1), 52-62.

Tiwari, V.V., \& Sharma, A. (2015). MADM for selection of vegetable based cutting fluids by SAW method and WPM method. International Journal of Research in Technology and Management, 1, $16-28$.

Yakowitz, D. S., Lane, L. J., \& Szidarovszky, F. (1993). Multi-attribute decision making: dominance with respect to an importance order of the attributes. Applied Mathematics and Computation, 54(2), 167-181. 